\title{
ARCO 2020: THE FIRST EDITION OF THE INTERNATIONAL CONFERENCE ON ART COLLECTIONS IN FLORENCE
}

\author{
Stefania Viti ${ }^{1}$
}

\section{CONCEIVING ARCO 2020}

\section{The background}

The International Conference ARCO 2020 has been promoted to focus the attention on art collections, joining different issues which play a fundamental role in their valorization, such as Cultural Heritage, Safety, Design and Digital Innovation. Each of these areas have produced important contributions, becoming essential research assets. Each research, in these years, has been developed within its proper field, and presented in many specific Conferences.

ARCO 2020 has been promoted with the belief that all the subjects focused on art collections should be developed jointly, or - at least - not ignoring each other.

The strong awareness of the multidisciplinary value of art exhibitions has increased within the research activity developed in these last years by some of the promoters of the Conference. The research team which promoted the Conference was born in 2016, with the research project named "RESIMUS" focused on the resilience of the art collections exhibited at the Museum of Bargello of Florence. The research, promoted by Stefania Viti and Giacomo Pirazzoli, activated many studies and projects, involving many researchers belonging to different fields, which started working together and producing many relevant contributions.

Unfortunately, the first edition of the Conference was not planned in a lucky period. The Conference has been planned for May 28-30; in Italy, the pandemic emergency started in March, at the end of the selection process of the papers to present at the Conference. The decision to postpone the Conference was taken in April; the new dates of the Conference were fixed in September (21-23), and an "hybrid" presentation mode was chosen, to give everybody the chance to participate. As a result, only the first day of the Conference occurred in a "live" way, whilst the final two days were managed through on-line connections. The organization of the live day was not easy, since there was the need to avoid any direct contact; a distance policy, together with other safety actions, must be observed in all the steps of the Conference.

\section{The involved areas}

The subject of the Conference consisted of art collections, together with all the issues involved in their exhibition, comprehension, preservation, restoration, et cetera. It was a huge theme, which involved many different branches of knowledges, and sensitivities. The multidisciplinary approach to art collection was the main value of the Conference, and it induced its "structure"; indeed, the Conference included four different issues, dedicated to as many areas:

Safety and diagnostic issue, chaired by Stefania Viti, aimed at assessing the vulnerability of the art collections to all possible hazards. In particular, the seismic vulnerability has been specially investigated, since in these last years many damages occurred to art works have been caused by earthquakes. Many types of art collections, such as sculptures and ceramics, result to be very sensitive to horizontal accelerations. Indeed, due to the possible slenderness, fragility of material, irregularity of the supports, oldness, they can hardly sustain horizontal accelerations.
${ }^{1}$ University of Florence, Department of Architecture. Italy. 
Italy, as well as many other countries, has a high seismic hazard, which should induce all the Museums' managers to take care of the seismic vulnerability of their collections.

Design and Museum Design issue, chaired by Francesco Collotti, was focused on the staging of the art collections. The formal choices related to the exhibitions of the art works, indeed, can be themselves object of art, and - however - affect the impact of visitors. Furthermore, the use of historical and monumental buildings as places for exhibition introduces a further complexity to face in the staging design. The site-specific museums, indeed, force the designer to combine the interest and the aesthetic value of the contents to those of the container; the effectiveness of the art collections' exhibition, therefore, is largely affected by the awareness and the capacity of the designer.

Digital Heritage issue, chaired by Giorgio Verdiani, collected the contributions related to the use of the new technologies for representing and exhibiting art collections. The new technologies, such as the digital applications, play a fundamental role in the involvement of people who visit the exhibitions. In these years, visitors' expectations regarding art exhibitions have grown a lot. The possibility to see art images in books, on websites, and other global platforms makes people more demanding as regards the visual properties of the setting, and the amount of expected information. Even the maintenance and the safety assessment of art collections take advantage by the digital technology, which leads an easy collection of large amounts of data.

Historical research issue, chaired by Alessandro Brodini, hosted the contributions aimed at understanding the cultural value of the art works, starting from their creation. The knowledge of the cultural and historical contest where a piece of art was conceived is essential for its full appreciation and valorization. The historical research is the first step for setting a good exposition of art collections.

\section{THE OPENING OF THE CONFERENCE}

The opening of the Conference was made in a "live" way. It took place in two different headquarters, both belonging to the University of Florence.

\section{The "opening" of the Conference}

The opening of the Conference has been organized in the Aula Magna of the University of Florence (Figure $1 \mathrm{a}, \mathrm{b}$ ). The main representatives of the University of Florence and of the Town of Florence contributed with a speech. Namely, there were Luigi Dei, Rector of the University, (Figure 1c), and Giuseppe De Luca, Incoming Director of the Department of Architecture (Figure 1d), who gave their contributions, and Giorgio Caselli, Director of the "Servizio Belle Arti" of the Town of Florence (Figure 1e), who explained the involvement of his office in the project. 

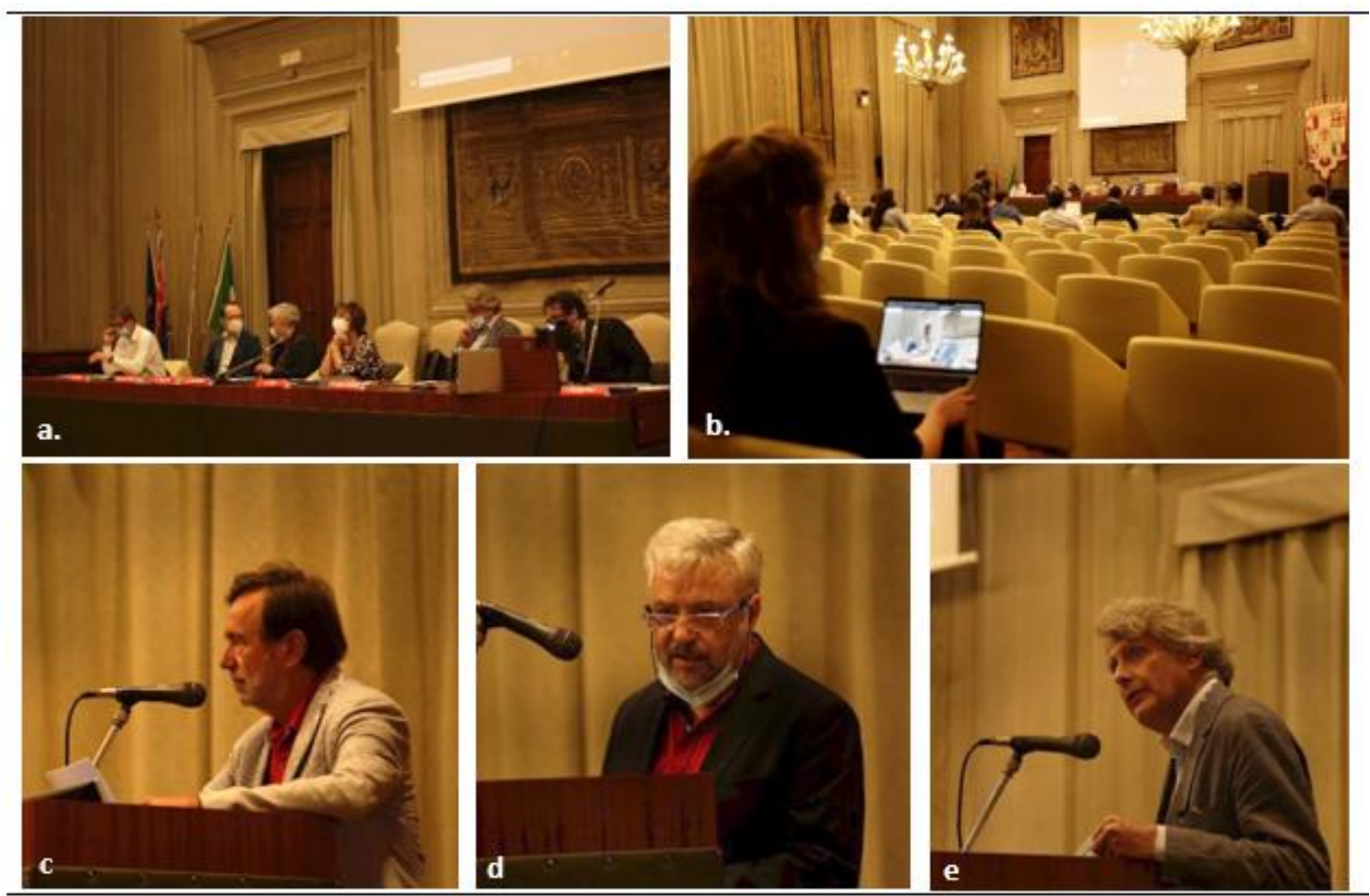

\section{The key-lectures}

The Conference went on with the invited guest of the session: Mauro Sassu (Figure 2), currently working as Full Professor at the University of Cagliari. He presented a lecture titled "Protecting the archaeological heritage from structural risks: some significant cases". The lecture presented the so called "Three R" strategy, that is based on "Respectful, Recognizable and Reversible" interventions for archaeological consolidation. The success of such strategy occurs when, after the intervention, i) the visitor can hardly distinguish the original parts from the reconstructed ones, or, even if recognizable, the reconstructed parts are visually respectful; ii) scholars can discern the interventions through a series of technical devices which can easily be recognized; iii) the owner of the building can make the intervention reversible, disassembling the changes if a better possible intervention would be available in the future.

Three well-known historical examples, which are part of the direct experience of Sassu, have been presented: two located in Arabic Peninsula (Dhofar district, Sumhuram- Al Balid), one in Jordan (Petra district - Shawbak).

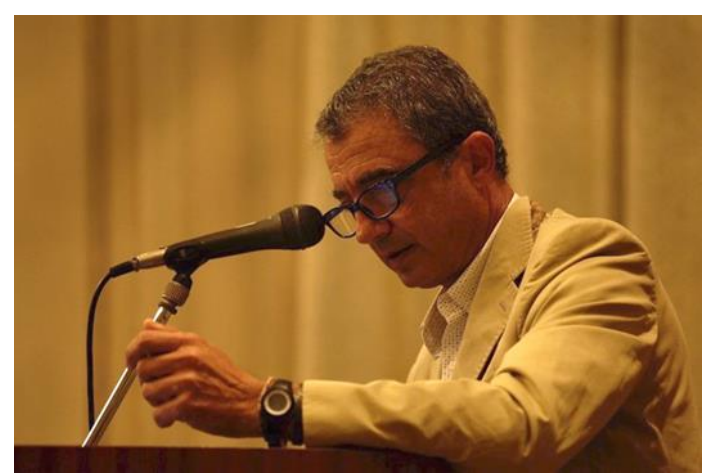

Figura 1. The Aula Magna of the University of Florence. a,b: views of the Aula Magna; c: Luigi Dei, Rector of the University of Florence; d: Giuseppe De Luca, Incoming Director of the Department of Architecture; e: Giorgio Caselli, representative of the Town of Florence

Figura 2. Mauro Sassu, invited speaker, during his intervention at the Conference's opening 


\section{The plenary presentations}

The plenary presentations consisted in four contributions, each of whom focused on one of the main issues proposed by the Conference. They took place in the rooms of another headquarter of the University of Florence, which are usually used for didactical purposes (see Figure 3a). Here below a brief description of the four presentation is resumed.

Safety and diagnostic. The plenary speech, titled "Correlation analysis between churches and their artistic content in terms of damage. A damage map of Italian Cultural Heritage through four Regions after the 2016 earthquake", was presented by Maria Pianigiani (see Figure 3b), working at the Ministero per i Beni e le Attività Culturali e per il Turismo. The contribution was focused on the losses suffered by the cultural heritage due to the strong earthquakes occurred in October and November 2016 and January 2017. The study presented by Pianigiani described the damages suffered by the contents, and the procedures activated by the proper offices to menage such damages, and to plan the recovery interventions. Namely, the churches affected by the earthquake have been almost 3000 in the four regions involved. After the previous assessment of their level of damage and of the related reconstruction's costs estimation carried out by technicians, on September 2017 the Italian Government have issued a funding plan for the reconstruction of the first 100 churches, chosen on the basis of the intervention's relevance.

Figura 3. Plenary section: the intervention of Maria Pianigiani in the
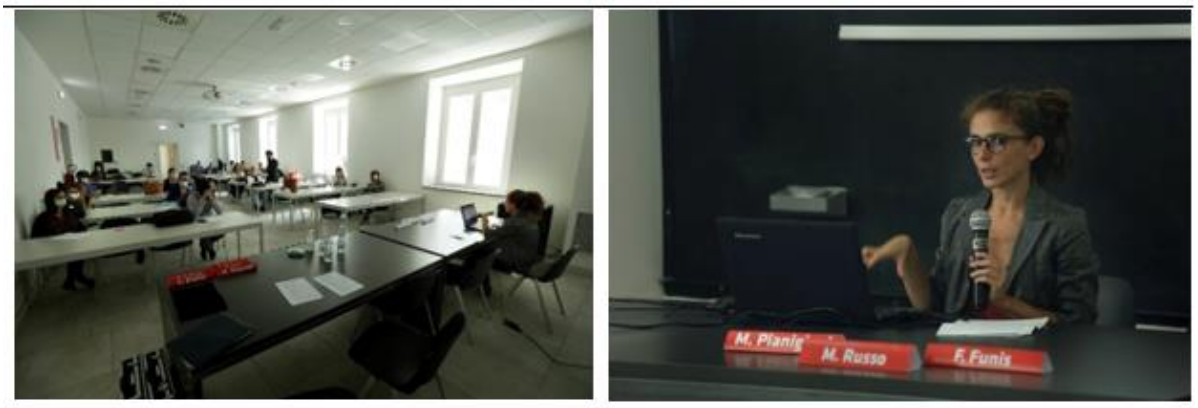

Design and Museum design. The speech, named "The gipso/TECA of the University of Perugia: conversion of a heritage building in a plaster cast gallery", was made by Riccardo Liberotti, from the University of Perugia. The work was focused on the reuse of historical buildings for art exhibitions. The selected case-study was the complex Palazzo Murena, designed by Luigi Vanvitelli and completed by Carlo Murena in 1762; currently owned by the University of Perugia. A comprehensive investigation has been made on the building, including a geometrical survey, which lead to understand the stratification of the different parts constituting the complex. An enhancement of the current structure has been planned, to provide the needed strength to the building. The interior layout is arranged to host the new functions including a linear exhibition that runs along the building's development by means of suspended pedestrian walkways, many galleries inside the central core and a new museum space at the top level of the masonry structure.

Digital heritage. The contribution, titled "CH representation between Monge's projections and Augmented Reality" was presented by Michele Russo, which currently works as Associated Professor at the Sapienza University in Rome. Russo presented a brief state-of-art of the changes of the Cultural Heritage representation occurred in the last twenty years. He proposed a though regarding the current compresence of different types of representation, such as orthogonal projections and 3D virtual models, and their potentiality in providing information and contributing to a satisfactory comprehension of the represented architecture/system/artifact. Dr Russo enriched his presentation with three examples, i.e. 
Delizia del Verginese, commissioned by the Este family at Portomaggiore, the San Sebastiano Gate in Rome and is one of the main and best-preserved gates of Rome, and the project - never realized - of the "Palazzina girevole" made by Pier Luigi Nervi.

Historical research. The contribution, named "The international consultation for the new exit on via dei Castellani and the Nuovi Uffizi", has been presented by Francesca Funis, from the University of Florence. The contribution was focused on the "Galleria degli Uffizi"; its development was described starting from the preliminary project of the "Nuovi Uffizi" (196465) up to the definition of the distributive aspects and the identification of the museum routes, in 1989. All the steps of the project, such as the Natalini's staircase and the international design competition for the exit square of the Uffizi Gallery in Piazza Castellani, have been presented and discussed. The intervention was a brilliant example of the importance of the knowledge of the detailed history of a building to fully understand its value and its meaning.

\section{THE TECHNICAL SESSIONS}

\section{The "live" interventions on September, 21}

The technical sessions of the first day occurred on September 21 in the afternoon, in the headquarters of the Architecture School of Florence. Some of the speakers went to Florence to attend the Conference despite the sanitary limitations, and the priority of the board was to let all of them to make their presentations in a "live" way. Therefore, three parallel sessions, including a "poster presentation", had been organized, to welcome all the speakers arrived in Florence.

All the presentations have been recorded and put on the website of the Conference, so that even the participants who could not go personally to Florence could attend the sessions and give their contribution.

The first oral session collected six contributions, belonging to the "safety and diagnostic" issue only. A special mention should be made to the intervention of Raffaele Gagliardo (University of Naples Federico II), who illustrated a Finite Element procedure appositely set to analyze blocky-structures subjected to uniform settlement, and applied to a monumental masonry church façade, and to the speech of Stefano Galassi (University of Florence) who spoke about a research focused on the ancient colonnade in the archaeological site of Pompeii (Italy).

The second oral session collected contributions of the other three issues. A special attention should be paid to the research presented by William Cortes Casarrubios (University of Udine), who showed a study made the Emilio and Annabianca Vedova Foundation in Venice, underlying the role of the friendship between the painter and Renzo Piano in the restoration of the building. Further interesting interventions were focused on other exhibitions, such as the Majolica Room of the National Museum of Bargello, archeological sites, and on the role of the digital techniques on the art safeguard and optimization.

Finally, the poster session (see Figure 4) hosted various contributions, ranging from numerical and experimental analyses to design experiences and digital applications. 
Figura 4. The poster session at the headquarters of the Architecture School of Florence (Santa Teresa rooms)
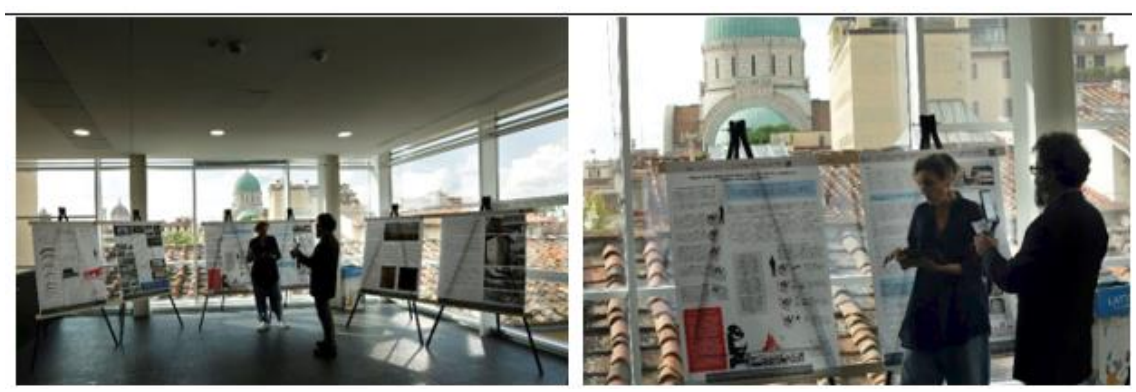

\section{The "on-line" interventions on September 22 and 23}

The further technical sessions occurred through the "on-line" way. Seven technical sessions occurred on line in September 22 and 23, which collected 36 contributions, plus a further session, organized as a round table, which closed the Conference.

All the presentations were interesting, and they would deserve to be described. For sake of brevity, here below only few of them will be mentioned.

Professor Emeritus Andrei Reinhorn, from the University of Buffalo, chaired a "Safety and diagnostic" session, and he presented a contribution titled "Monumental buildings used as museums: protection or danger for the artifacts?". The speech underlined the crucial role of the buildings which host art collections as regards their safety. Indeed, such buildings are supposed to protect the art goods from natural and human hazard; unfortunately, in many cases they not only do not provide such protection, but they can represent a further danger, due to their intrinsic vulnerability. Such problem becomes even more relevant when monumental and historical buildings are used as museums, since - in many cases -they are made without complying the current safety requirements.

Another very interesting contribution has been made by Beatrice Mazzanti (University of Florence), who talked about the Exhibition of the Italian garden which occurred at Palazzo Vecchio (Florence) in 1931. The gardens, indeed, can certainly be considered as a form of art; the research was addressed to the "giardini all'Italiana", and, namely, to the "teatrini", i.e. a group of ten modern dioramas that showed the main stylistic phases of the historic Italian garden.

Finally, a special mention to Paola Lupo, from the University of San Paolo, who proposed a study on the contemporary multimedia museums, focusing on the "Museum of Tomorrow", in Rio de Janeiro, taken as a significant example of the creation of architecture and museography. In the research, a systematic observation of the visitors, known as "tracking and timing", was made, and the collected data have been used for pointing out possible improvements.

\section{THE SOCIAL ACTIVITIES}

A special attention was been paid to the social activities related to the Conference. Due to the sanitary limitations, indeed, it was not possible to have free times to talk besides the technical sessions. Usually, Conferences give the opportunity to learn new knowledges, but even to be in contact with new research groups, and to speak informally about the topics of the technical sessions; there are coffee-breaks, work-lunches, and other free times, which give to the researchers attending the Conference the opportunity to speak together and get closer to the most interesting issues experienced during the technical sessions. 
Since it was not possible to provide such "free times" inside the Conference buildings, a "social evening" was organized, consisting of a welcome cocktail and two art exhibitions.

\section{The welcome cocktail}

The welcome cocktail has been organized in the garden of a Florentine Villa (Villa Viviani, shown in Fig. 5), an historical house on the hills around Florence.

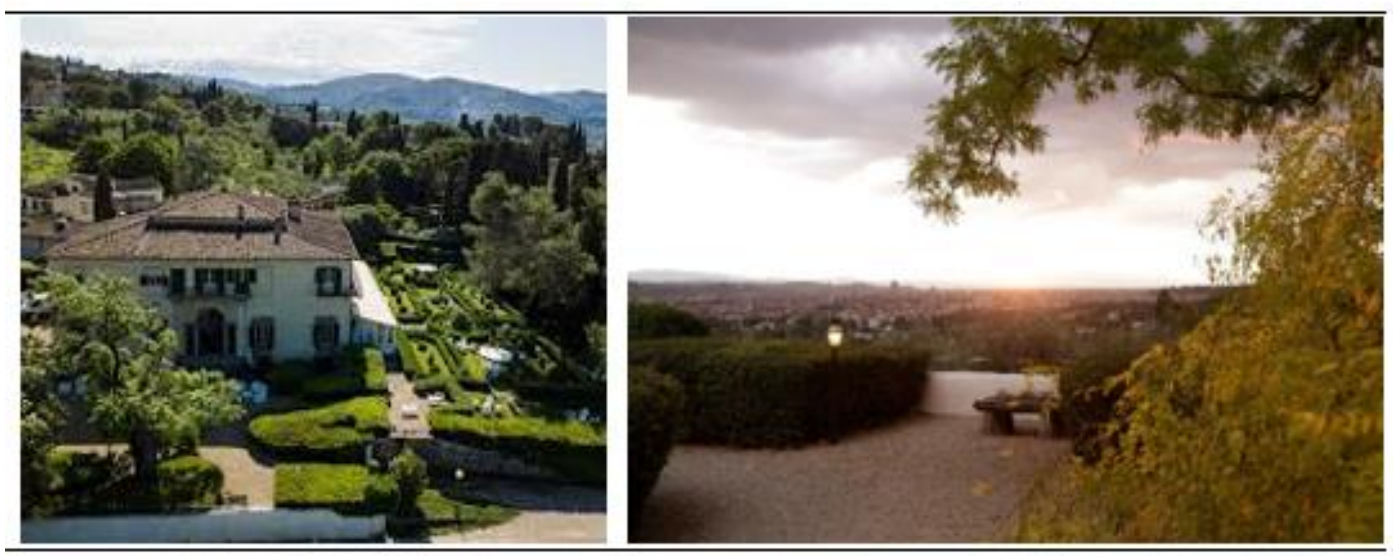

Villa Viviani dates back to the XIII century, and it experienced many transformations and many owners. At the beginning of the XX century, the writer Mark Twain lived in Villa Viviani, using the Villa as location for one of his novels (Pudd'nhead Wilson).

The welcome cocktail (see Figure 6) gave the opportunity to spend time together in a safe way, eventually developing discussions started from the technical presentations.
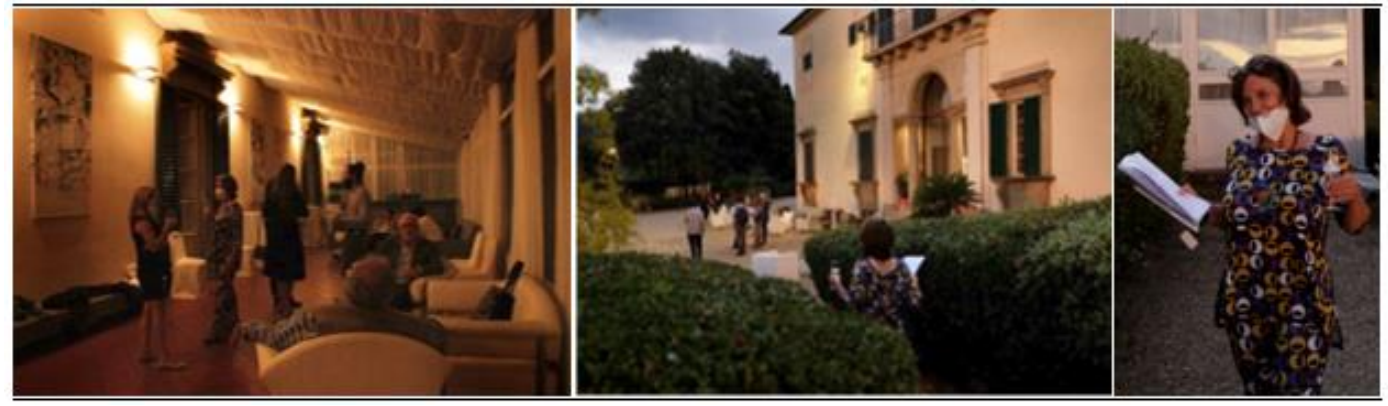

\section{The art exhibitions}

Within the social evening, some special guests were invited, to give an extra value to the Conference. Namely, a lectio magistralis made by Moni Ovadia and a concert of piano made by Alessandra Garosi (see Figure 7) were proposed.
Figura 5. Villa Viviani: the Villa and the view

Figura 6. Welcome cocktail at Villa Viviani. 
Figura 7. Alessandra Garosi at the piano

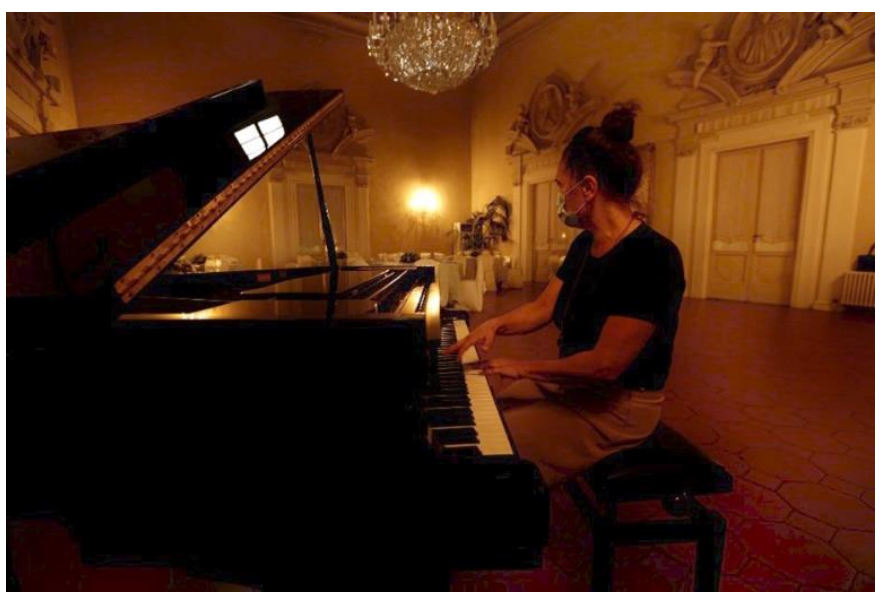

Both music and speech can be considered as art exhibition. Art is "fluid". It grows taking advantage from various experiences and features; it becomes continuously something different. The cultural heritage reminds us where we come from without placing any barrier, or any separation among people of different countries and traditions. It is not really possible to completely distinguish the role of the architectural goods from that of other forms of art, such as sculpture, painting, and music. As well as it happens with words, which have ever been a way to express concepts, but even emotions, and which had an extraordinary role in constructing our cultural identity.

For this reason, the Lectio Magistralis and the concert are proposed not only as an entertainment activity, but even as integrated contribution to the contents proposed by the Conference. Both the artists (see Figure 8) have an international profile, and a carrier distinguished for the "diversity" of their productions.

The speech of Moni Ovadia, named "Art, Culture, Pietas", was focus on the role of art and beauty as instruments of development and integration for marginalized people; the concert proposed some pieces, from different authors (i.e. J.S. Bach, Heitor Villa Lobos, Kanji Funtsu and Damiano Santini), inspired to the nature, that was assumed to play a special role in the "universal" perception of the beauty. 


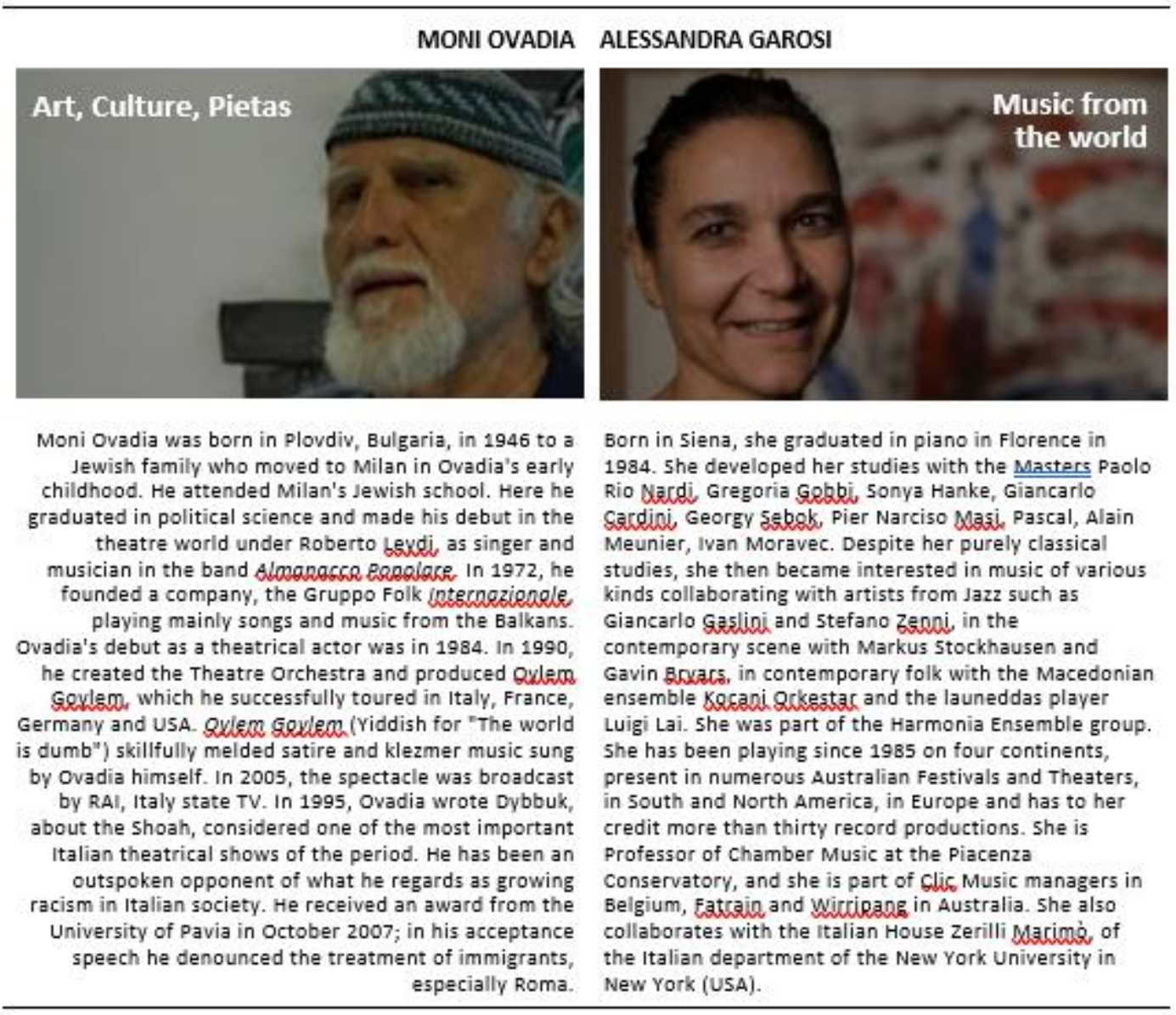

Figura 8. The guests of the social evening

\section{OUTCOMES AND AIMS}

The first edition of the Conference had to deal with a very unusual situation, which lead to change the timing, the organization, and the presentation modality. Finally, the board was very satisfied of the results, which took advantage form the effort and the contribution of all the participants.

The Technical Sessions collected many interesting contributions, whose originality and diversity gave a special value to the Conference. All the papers presented at the Conference will be published. Different Conference Proceedings will be made, according to the different research areas involved in the Conference. The Safety and Diagnostic contributions have been already published in an Scopus-indexed open-access book of the series "Procedia Structural Integrity", which is available on line (https://www.sciencedirect.com/journal/procediastructural-integrity/vol/29/suppl/C). The papers belonging to the other fields are still in the editing process, but they will be available soon. A further book will be published to collect the extended abstracts of all the contributions, in order to have a synthetic and comprehensive document which expresses the scientific outcome of the Conference; even this book is in the editing process.

Furthermore, a special issue dedicated to the 1st ARCO Conference, named "New Approaches in Diagnostic and Safety Evaluation of Cultural Heritage" will be published in the International Journal of Masonry Research and Innovation 
Stefania Viti

stefania.viti@unifi.it (https://www.inderscience.com/jhome.php?jcode=ijmri). The Special Issue will collect some of the presented papers, which will be enhanced, in order to present original contents.

Personally, I guess that the Conference had a positive outcome, collecting many studies and contributions of different fields, connected to each other just by the object of the Conference: Art Collections. The need to valorize, to protect, to enhance them require to dedicate a further effort, and to go on with the research. One of the main goals of the Conference was to encourage the interdisciplinary research on art collections. The Conference certainly represented an achievement in this direction, obtaining important results. Nevertheless, there is a lot of work still to do.

The wish of the board is that the research activities presented at the Conference can go on, developing new attainments, and becoming more and more connected to each other. In 2022, if the global sanitary situation will be overcome, a further edition of the Conference will be organized. The second ARCO Conference will take place in Florence again, since one "live" day only has been possible in this first experience, and the attendants had not the opportunity to take advantage from the copious artistic attractions of the town. Florence, as the cradle of Renaissance, seems to be an optimal place to represent different forms of art, and to show how they can merge with other knowledge sources, with the result of valorizing each single art good.

I really hope that the second edition of the Conference will have the same success of the first one, and that ARCO Conference can become a benchmark for art collections. 